\title{
Analysis of the Results of Accelerated Aging Tests in Insulated Gate Bipolar Transistors
}

\author{
Daniel Astigarraga, Federico Martin Ibanez, Ainhoa Galarza, Member, IEEE, Jose Martín Echeverria, \\ Inigo Unanue, Piero Baraldi, and Enrico Zio
}

\begin{abstract}
The introduction of fully electric vehicles (FEVs) into the mainstream has raised concerns about the reliability of their electronic components such as IGBT. The great variability in IGBT failure times caused by the very different operating conditions experienced and the stochasticity of their degradation processes suggests the adoption of condition-based maintenance approaches. Thus, the development of methods for assessing their healthy state and predicting their remaining useful life (RUL) is of key importance. In this paper, we investigate the results of performing accelerated aging tests. Our objective is to discuss the design and the results of accelerated aging tests performed on three different IGBT types within the electrical powertrain health monitoring for increased safety (HEMIS) of FEVs European Community project. During the tests, several electric signals were measured in different operating conditions. The results show that the case temperature $\left(T_{C}\right)$, the collector current $\left(I_{C}\right)$, and the collector-emitter voltage $\left(V_{\mathrm{CE}}\right)$ are the failure precursor parameters that can be used for the development of a prognostic and health monitoring (PHM) system for FEV IGBTs and other medium-power switching supplies.
\end{abstract}

Index Terms-Accelerated aging tests, fully electric vehicle (FEV), insulated gate bipolar transistor (IGBT), prognostic and health monitoring (PHM).

\section{INTRODUCTION}

$\mathbf{P}$ OWER converters have become an essential subsystem in several industrial applications. However, their failure can cause system losses, abrupt stoppages, long maintenance times, and high costs. Therefore, in applications where system

Manuscript received July 16, 2015; revised November 30, 2015; accepted December 21,2015. Date of publication December 29, 2015; date of current version June 24, 2016. This work was supported in part by the European Community's Framework Programme FP7/2007-2013 under Grant 314609 (www.hemis-eu. org). The work of D. Astigarraga work was supported by the Basque Government under Grant PRE_2014_2_200. The work of A. Galarza was supported in part by the Basque Government project TIPOTRAN. The work of P. Baraldi was supported by the European Union Project Innovation through Human Factors (INNHF) in risk analysis and management. The work of E. Zio was supported by the NSFC of China under Grant 71231001. Recommended for publication by Associate Editor Andreas Lindemann.

D. Astigarraga, F. M. Ibanez, A. Galarza, and J. M. Echeverria are with the CEIT and TECNUN, University of Navarra, San Sebastian 20018, Spain (e-mail: dastigarraga@ceit.es; fmibanez@ceit.es; agalarza@ceit.es; jmecheverria@ceit. es).

I. Unanue is with the JEMA Energy (IRIZAR Group), Lasarte-Oria 20160, Spain (e-mail: i.unanue@jemaenergy.com).

P. Baraldi is with the Dipartimento di Energia, Politecnico di Milano, Milan 20133, Italy (e-mail: piero.baraldi@polimi.it).

E. Zio is with the Dipartimento di Energia, Politecnico di Milano, Milan 20133, Italy, he is also with the Ecole Centrale Paris and Supelec, Chair System Science and the Energy Challenge, Fondation Electricité de France, CentraleSupélec, 92290, Chatenay-Malabry, France (e-mail: enrico.zio@ecp.fr, enrico.zio@supelec.fr). reliability must be guaranteed, detecting the onset of power converter degradation, and predicting its RUL has become an issue of major interest [1]-[3].

The development of pulsewidth-modulated (PWM) switching power supplies has led to the application of insulated gate bipolar transistor (IGBT) in several industries such as railway, aerospace, and automotive [4], [5].

In this paper, we consider IGBT used in fully electric vehicle (FEV) powertrain. The automotive industry is especially affected by systems failure due to the high impact on customers' image of the brand. Opinion polls show that consumers are concerned about the reliability of FEV technology, reliability is one of the main reasons why potential consumers would choose a hybrid vehicle instead of an FEV [6]. Hence, the business case for electric vehicles is affected by component performance and lifetime issues, and any failure in this field can potentially damage the consumer confidence.

In [7], it was shown that the two most critical components in FEV converters are the dc-bus link electrolytic capacitor and IGBTs. Within the European Project HEMIS, the possibility of developing a prognostic and health monitoring (PHM) system for dc-bus-link electrolytic capacitors in order to alert drivers of component degradation and allow maintenance to be performed was considered [8].

With respect to IGBTs, the highly demanding operating conditions (high cooling system temperatures, vibrations, shocks, particular thermal and humidity conditions, etc.) of FEVs [4], [5] tend to reduce their lifetimes and compromise overall system reliability. A possible solution for improving system reliability, reducing maintenance costs and improving consumer impressions is to develop automatic systems that identify IGBT degradation and predict their failure times.

The development of a PHM system for IGBT monitoring in FEVs requires:

1) identifying the signals to be monitored;

2) developing and implementing low-cost sensors;

3) developing monitoring algorithms;

4) deploying the whole system.

Although the problem of IGBT monitoring has been addressed in several studies [1], [5], [9], the novelty of this paper is to consider monitoring FEV IGBTs, both with novel sensors and laboratory equipment, in order to assess their real application capabilities for monitoring. FEV IGBTs operate in variable and highly demanding conditions, and it is not possible to measure all the signals considered in [1], [5], [10], and [11] mainly due to the intrusiveness, high cost, and low reliability of some of these measurements. Given the lack of information and data 
regarding FEV IGBT degradation, the main objective of this paper is to discuss the design and results of laboratory accelerated degradation tests. The use of commercial sensors together with laboratory equipment will also allow us to analyze whether they are accurate enough to detect the variations due to degradation.

The results of this research will make it possible to identify which of several candidate signals will be the best for FEV IGBT monitoring as well as collect the necessary information and data in order to develop PHM models for FEV IGBTs.

Accelerated aging tests are a common practice for assessing the reliability of electronic components [4], [12], [13], [14]. In [4] and [14], accelerated aging tests were performed on IGBT modules for automotive applications. Electrothermal aging was considered in both papers, in which the junction temperature was driven to values higher than its maximum nominal value. Different test procedures were applied: dc and PWM signals were applied to the gate and their influence on the degradation process was analyzed. The authors observed changes in the values of collector-emitter on-state voltage $\left(V_{\mathrm{CE}, \mathrm{ON}}\right)$ and thermal resistance $\left(R_{\mathrm{TH}}\right)$ before IGBT failure. In [15], degradation was induced by considering temperature values well above the nominal, observing over $315^{\circ} \mathrm{C}$ on the case. Changes in component transconductance, collector-emitter on-state voltage, and threshold voltage were observed during the degradation process. Celaya et al. [12] developed an accelerated aging system for different kinds of semiconductors. Since the study was focused on electrical stresses, the accelerated test conditions were attained by electrical operation of the devices at temperatures within the range that was below maximum ratings and above room temperature. This was done by controlling the case temperature. Changes in threshold voltage were observed.

Accelerated aging tests allow the effects of failure mechanisms to be analyzed and failure precursor indicators to be identified. In this study, accelerated degradation was conducted through electrothermal cycling, which induces thermal fatigue degradation. This was selected due to its similarity to real operating conditions in FEVs IGBTs. Notice that this type of accelerated tests allows the IGBT real operating conditions to be replicated and the IGBT degradation process to be reproduced in a reduced time.

Three different types of discrete IGBTs were selected for testing: IR's IRG4BC30KDpbf punch-through IGBT, FUJI's FGW15N120VD Trench Field-Stop IGBT, and the IXYS IXXN110N65C4H1 Trench XPT GenX4 IGBT. The IR IGBT was selected in order to compare the results with those from previous studies [15] and to validate the selected methodology. The other two IGBT types were selected to represent new IGBT technologies. The FUJI and IR IGBTs have similar packages and nominal currents. The IXYS IGBTs are characterized by a higher nominal current than the other two types.

\section{MONITORING VARIABLES}

The implementation of several candidate variables was studied in order to assess the degradation. After performing a failure mode and effects analysis (FMEA) of the different components, the main failure mechanisms were identified and precursor parameters were analyzed [16]. Widely used variables for monitoring the condition of semiconductor components are: junction-to-case thermal resistance $\left(R_{\mathrm{TH}}\right)$, collector-emitter on-state voltage $\left(V_{\mathrm{CE}, \mathrm{SAT}}\right)$, on-state resistance $\left(R_{\mathrm{ON}}\right)$, gate signal monitoring, and switching time analysis [10], [11], [15].

Thermomechanical fatigue stresses have been reported to be the main degrading force for power devices due to packaging materials [10]. The different failure mechanisms are mainly driven by the swings in junction temperature, which is highly related to the number of cycles the component can endure [17]. The main failure mechanisms are the consequence of the different coefficients of thermal expansion (CTE) of the layers of the IGBT.

The most frequently reported package-related failure modes are bond-wire liftoff and solder fatigue [10], [11]. Bond-wire liftoff is consequence of crack growth at the bond wire/chip interface. Solder fatigue is the propagation of cracks or voids between the module substrate and base plate.

Other common failures are chip-related failures. Some examples are charge effects/hot carrier injection, gate oxide breakdown, electromigration, and latch-up [11]. These chip-related failures are the ones that ultimately appear when the IGBT breaks down. As a consequence, the monitoring system should be able to detect changes related to all the previously explained degradation mechanisms.

The on-board monitoring system was constrained by the manufacturers consulted during the research phase, who specified that the system must be nonintrusive, highly reliable, and cost efficient. Nonintrusive is understood to mean that the impact of the changes made to the monitored system must be small from the manufacturing point of view in order to be an acceptable method. Taking this into account, junction temperature and thermal resistance monitoring were discarded, because of their high intrusiveness [5], [14]. Gate signal monitoring and switching time analysis demand high-precision sensors, sampling rates, and processing memory, thereby increasing overall costs [1].

Based on previous tests and preliminary results, the following variables were selected for further study in a first test campaign: case temperature $\left(T_{C}\right)$, gate current $\left(I_{G}\right)$, gate voltage $\left(V_{G}\right)$, collector current $\left(I_{C}\right)$, and collector-emitter voltage $\left(V_{\mathrm{CE}}\right)$. These signals were monitored during the different tests that will be explained in Section $\mathrm{V}$ below. However, after the degradation tests, it became clear that the triplet data formed by the accurately measured $I_{C}, T_{C}$, and $V_{\mathrm{CE}}$ variables were appropriate for prognostics. Hence, these variables were selected for the final system. The gate current and gate voltage measurements were not included because previous test experiments demonstrated that the required sampling frequency $(\mathrm{MHz})$ and measurement accuracy were too high. Introducing them into the final system was also considered very intrusive.

\section{MEASURING TYPES}

Three different measurement types were carried out during characterization of the degradation process: continuous measurements during the degradation process, discrete 
measurements after each degradation process step, and measurements during normal operating conditions in a switching frequency inverter with an $a d$ hoc designed prototype.

\section{A. Continuous Measurements During Degradation Cycles}

Continuous degradation measurements of the three variables $\left(I_{C}, T_{C}, V_{\mathrm{CE}}\right)$ were collected during each 100 degradation cycles. Although this kind of measurement is noisy and includes some transient information, it allows the dynamic behavior of IGBTs to be studied for a given collector current and case temperature range. This process makes it possible to compare the behavior of the different IGBTs operating under the same conditions. The sampling frequency of this process was established to $10 \mathrm{~Hz}$.

\section{B. Discrete Measurements After Degradation Cycles}

After each of the 100 degradation cycles had finished, discrete measurements were taken. These measurements were taken only when the IGBT reached room temperature. The main characteristic of these measurements is that the signals were less noisy and, therefore, easier to analyze, and the procedure was controlled and repeatable. There were two types of discrete measurements. On the one hand, the threshold voltage $\left(V_{\mathrm{GE}, \mathrm{TH}}\right)$ was measured. $V_{\mathrm{GE}, \mathrm{TH}}$ is understood as the minimum gate voltage for the IGBT to be considered in the on state. The gate voltage was slowly increased until the flowing current value showed a dramatic change, meaning the IGBT was on. During the process, the gate voltage was accurately monitored and recorded. The current supplied to the IGBT was limited to $250 \mathrm{~mA}$ in order to keep low the heating rate and the temperature as constant as possible, but big enough to observe the change. The second measurement focused on $V_{\mathrm{CE}, \mathrm{SAT}}$. $V_{\mathrm{CE}, \mathrm{SAT}}$ is $V_{\mathrm{CE}}$ value at which the IGBT is in the on state while a set current value flows through the collector. The IGBT was switched on for $3 \mathrm{~s}$, letting a fixed current rate of $10 \mathrm{~A}$ flow. The sampling frequency of these measurements was $100 \mathrm{~Hz}$.

\section{Continuous Measurements Under Normal Operating Conditions}

The final measurement mode was only applied to the IXYS IGBTs. The three variables $\left(I_{C}, T_{C}, V_{\mathrm{CE}}\right)$ were measured during IGBTs operation under normal operating conditions in the inverter. The switching frequency of the inverter was $10 \mathrm{kHz}$, and the modulation frequency was $50 \mathrm{~Hz}$. The inverter was connected to a resistive load of $2 \Omega$. The inverter had a cooling plate attached. The sampling frequency of these measurements was $20 \mathrm{kHz}$

\section{Circuits AND SEnSORS}

The research was split in two different steps, involving one different circuit for each step. The first step (see Section IV-A) studied IGBT degradation in order to characterize it. The influence of the degradation on the selected preliminary variables needed to be studied. Given the uncertainty of the impact that degradation would have on them, the precision

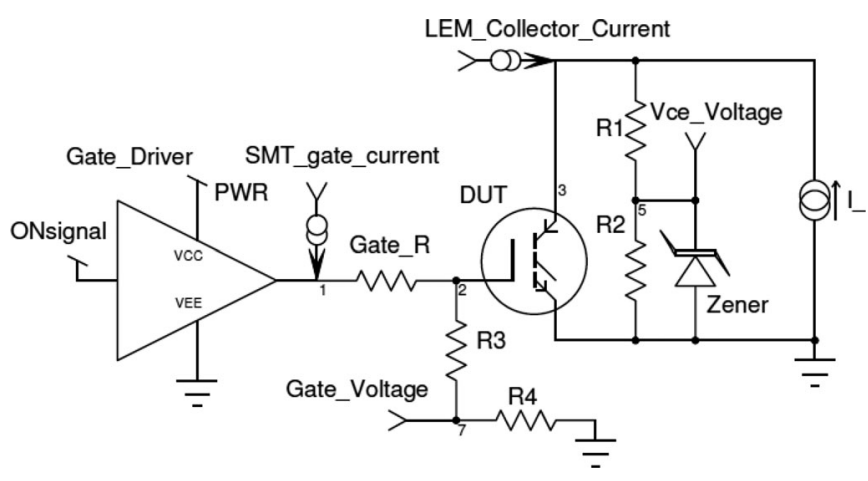

Fig. 1. IGBT degradation.

required was high; therefore, tests were run with high accuracy laboratory instruments. From the outcome of these tests, the final set of variables was selected. The second test stage (see Section IV-B) was intended for degraded IGBT and consisted of measuring the selected variables under normal operating conditions. Therefore, an ad hoc circuit was developed for online measurement. The online measurement was tested with an inverter connected to a resistor load.

\section{A. Degradation Characterization Circuit}

Due to the low variation in signals levels and the low signalto-noise ratio, an accurate recording of the data was required. A 16-bit resolution laboratory data acquisition system was needed, so the NI USB-6259 from National Instruments was used. It has a maximum sampling rate of $1.25 \mathrm{Ms} / \mathrm{s}$, which is sufficient for this purpose. The degrading current was set to a maximum of 17 A due to power supply limitation and also for safety reasons, as failure of the IGBT is expected. The sensors' circuit was built taking into account the fact that the same board should be able to degrade the component and measure the variables.

To measure $V_{\mathrm{CE}}$, a Zener diode and a resistive divisor were used in order to measure the voltage when the IGBT was both on and off and under transient conditions. The gate current was measured through the CST1-020lb SMT current sensor from Coilcraft. The gate voltage was directly measured through a resistive divisor. The collector current was measured through a Hall-effect current transducer model LTSR-15NP. The selected temperature sensor was a K-type thermocouple from Omega. The schematic of the circuit used to degrade the IGBT and take the measurements is shown in Fig. 1.

To degrade the IXYS IGBT, some modifications were required. The IXYS is capable of carrying $110 \mathrm{~A}$ in nominal conditions at case temperature of $110^{\circ} \mathrm{C}$. Given the power limitations of the power supply, it would take a long time to heat it up with $17 \mathrm{~A}$, and thus, a resistive divisor at the gate that set the operating conditions in the active region was built. As a result, a power loss of $60 \mathrm{~W}$ was dissipated.

\section{B. Ad hoc Prototype}

A second measurement circuit was built in order to test degraded IGBTs under normal operating conditions within an 
inverter. The aim was to test not only that the selected variables and sensors were appropriate for online prognostics but also that the measurement procedure was correct and whether it allowed the degradation to be assessed online. This way, an inverter was also built for testing the degraded IXYS components under load.

In this new framework, a sensor system prototype that was closer to what could be integrated in the vehicle for on-board monitoring was developed. Current was measured with an LEM HTFS-200P. The temperature sensor used was the same one used in the previous setup. Finally, $V_{\mathrm{CE}}$ was sensed through a new sensor from IR, the IR25750. Although it is intended to be an indirect current measurement sensor, it perfectly meets the requirements for the online prognostic purposes of $V_{\mathrm{CE}}$. Additionally, it can be easily placed on the gate driver board, and thus, it is considered to be nonintrusive. Extra sensors were placed for phase voltage sensing (LV-25).

\section{Measurement Accuracy Considerations}

A critical challenge for the degradation characterization and ad hoc prototype is the measurement accuracy of the signals. Absolute accuracy for analog inputs was evaluated for the NI USB 6259. A nominal range of $\pm 5 \mathrm{~V}$ was selected to run the calculations. The procedure developed is established within the component datasheet [18]

$$
\begin{aligned}
& \text { Absolute Accuracy }=\text { Reading } \times \text { Gain Error } \\
& + \text { Range } \times \text { Offset Error }+ \text { Noise uncertainty } .
\end{aligned}
$$

The outcome of 1 was an absolute accuracy of $1.012 \mathrm{mV}$ with values extracted from the datasheet of the component. The accuracy of IR25750 is directly related to the accuracy of the data acquisition system, as it has a signal transfer ratio of 0.98 . This makes the IR sensor suitable when accurate measurements are required. The LTSR 15-NP current transducer was selected due to its sensitivity of $41.6 \mathrm{mV} / \mathrm{A}$ and accuracy of $\pm 0.2 \%$. Finally, the K-thermocouple sensor adapter device accuracy at full scale is $\pm 1 \%$. All in all, the total error due to the measuring system was less than $5 \mathrm{mV}$ on the most critical variable, namely, $V_{\mathrm{CE}}$. Provided that the range of variation observed for $V_{\mathrm{CE} \text {.SAT }}$ due to the degradation is around $50-100 \mathrm{mV}$, the accuracy of the measuring system is concluded to be acceptable. For an online monitoring system, the selected sensors together with a careful selection of an ADC instead of the NI USB would make it possible to build the system with enough measurement accuracy at a reasonable cost.

\section{AgING Mode}

A thermoelectric degradation process was carried out. More precisely, 7 IR IGBTs, 5 FUJI IGBTs, and 18 IXYS IGBTs were subjected to aging tests. As the IGBTs had no forced cooling system, their turn on/off process depended on the case temperature. This meant the IGBT was turned on until it heated up to a given maximum threshold; then, it was turned off in order to cool it down, until a minimum threshold was reached. Afterward, the cycle started again and repeated. The process was stopped after 100 toggling cycles. Each of the thermal cycles

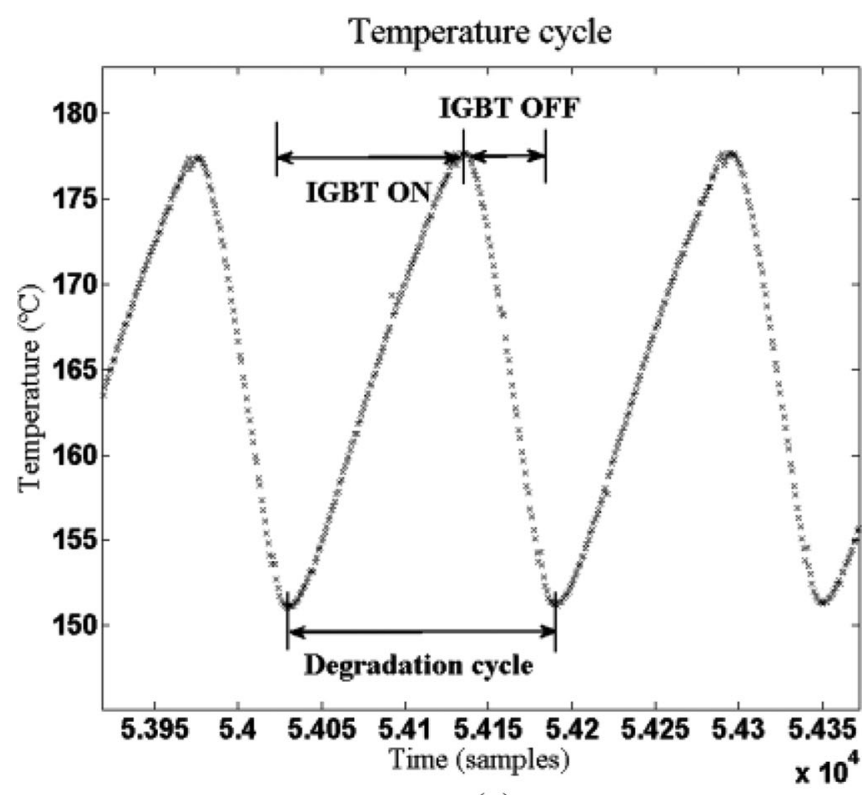

(a)

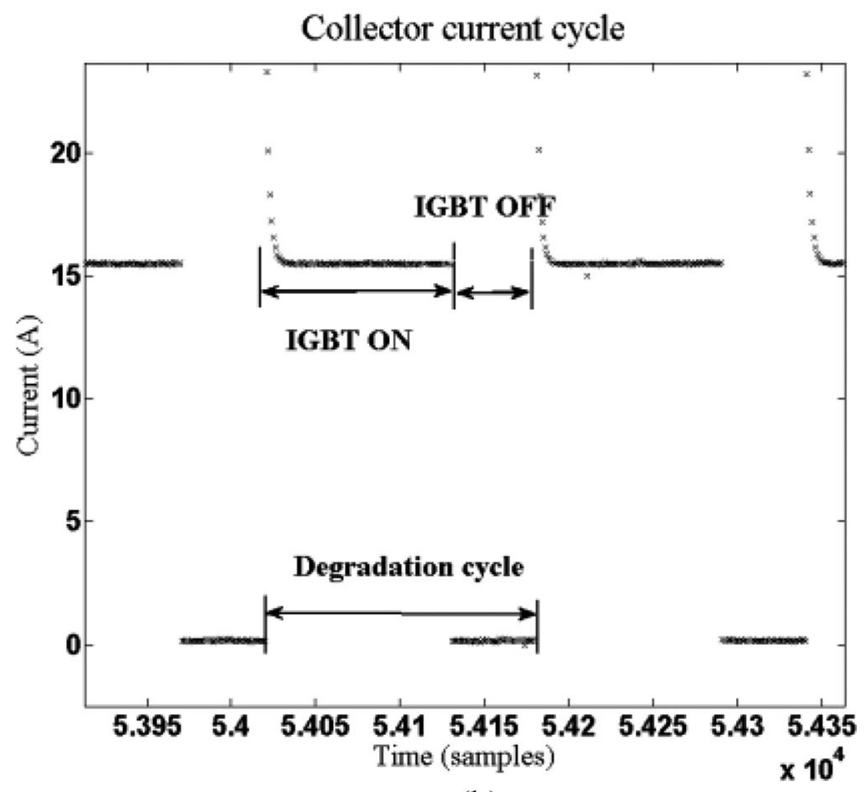

(b)

Fig. 2. (a) Degradation temperature profile; (b) current profile.

took around 10-12 s. The temperature and current profiles for two complete cycles can be seen in Fig. 2 .

Next, the discrete measurements explained previously ( $V_{\mathrm{GE}, \mathrm{TH}}$ and $\left.V_{\mathrm{CE}, \mathrm{SAT}}\right)$ were taken and the degradation process was restarted. The process was stopped when the IGBT gate control was lost (latch-up) or it suffered an internal short circuit, except for the case of IXYS IGBTs, where the process was stopped before they became completely damaged so that they could be tested in normal conditions afterward. The number of aging cycles endured by each IGBT is shown in Table I.

The selected IGBTs have different maximum junction temperature values. This is due to their manufacturing technologies. FUJI and IXYS use newer technology than IR. As previously 
TABLE I

NuMBER OF THERMAL CyCLES ENDURED

\begin{tabular}{lccccccr}
\hline \hline IGBT Type & 1 & 2 & 3 & 4 & 5 & 6 & 7 \\
\hline FUJI & 1524 & 2100 & 2150 & 2803 & 5200 & & \\
IR & 710 & 704 & 500 & 400 & 300 & 400 & 328 \\
\hline \hline
\end{tabular}

TABLE II

Degradation CASE TEMPERATURe VAlues

\begin{tabular}{lcc}
\hline \hline IGBT Type & $T_{\mathrm{C}, \mathrm{min}}\left({ }^{\circ} \mathrm{C}\right)$ & $T_{\mathrm{C}, \max }\left({ }^{\circ} \mathrm{C}\right)$ \\
\hline IR & 120 & 160 \\
FUJI & 150 & 180 \\
IXYS & 250 & 270 \\
\hline \hline
\end{tabular}

noted, the IR IGBTs are PT technology with $T_{J \text {, max }}=125^{\circ} \mathrm{C}$ and $I_{C, \text { nom }}=16 \mathrm{~A}$. The Trench FS FUJI can carry the same nominal current but with $T_{J, \max }=175^{\circ} \mathrm{C}$. Finally, the XPT IXYS can carry $I_{C, \text { nom }}=110 \mathrm{~A}$ with $T_{J, \max }=175^{\circ} \mathrm{C}$. The IGBT package and design technology had a great influence on the number of life cycles they could endure [17]. The number of cycles each IGBT type would last was initially unknown. Therefore, preliminary tests were conducted at different temperatures in order to select the degradation temperatures. The selected temperature values were measured at the case of the IGBT. Thus, the junction temperature would be beyond the maximum thresholds established in the datasheet, driving a fast degradation procedure. The degradation was driven with low current values compared to the maximum of the IXYS IGBTs; therefore, it was seen that the degradation was slower for the temperature values employed with the other two IGBTs. As a result, an increase in the average degradation temperature was applied, reaching $250^{\circ} \mathrm{C}$. This value was observed to degrade the component at a faster pace without destroying it. The selected degradation temperatures are in Table II. Although the degradation values are different, it is possible to compare the results given the following statements. The behavior due to degradation was not analyzed by only taking into account the temperature; instead the ensemble behavior of $I_{C}, T_{C}$, and $V_{\mathrm{CE}}$ variables was analyzed. This showed trends that were comparable for the different IGBT types. It must be noted that if the thresholds shown in Table I had been increased further, the degradation process would have been too severe and the components would have suffered irreversible damage after a few cycles. The IXYS IGBTs were degraded following a continuous process, that is, the degradation process was not stopped every 100 cycles to take discrete measurements. Thus, the data available for discrete measurements were taken at the end of the whole degradation process; this fact is represented in the different shapes of the figures shown below. Their degradation process was set to a certain number of cycles, based on previous tests. Six IGBTs were degraded at 900 cycles, six IGBTs were degraded at 1800 cycles, and another six were degraded at 2700 cycles; therefore, the process was stopped before any of them failed. This yielded degraded IGBTs at different levels that were still operational.

\section{RESULTS}

First, the goodness of the aging method is analyzed. The observed mean and standard deviation for the FUJI IGBTs failure is 2755.4 and 1438 cycles, respectively. For the IR IGBTs, the mean is 477.42 and the standard deviation is 169.16 cycles. These numbers will not apply exactly to a higher sample of IGBTs. However, these numbers let us assume that the tests have good repeatability, showing values in the same order of magnitude for the same IGBT types. Hence, we can assume that the tests are reliable enough to make qualitative conclusions that could apply to a greater number of components.

The results are now presented. $V_{\mathrm{GE}, \mathrm{TH}}$ and $V_{\mathrm{CE}, \mathrm{SAT}}$ from the discrete measurements are initially shown. Then, the degradation patterns obtained from the continuous measurements during the degradation cycles are presented. Finally, data from continuous measurements under the normal conditions is shown and the possible failure mechanisms are analyzed.

\section{A. Discrete Measurement: $V_{\mathrm{GE}} \mathrm{TH}$}

$V_{\mathrm{GE}, \mathrm{TH}}$ evolution for the life cycle of the IGBTs is shown in Fig. 3. The discrete measurements were only taken at the beginning of each 100 cycles; however, for the sake of clarity, the values of $V_{\mathrm{GE}, \mathrm{TH}}$ are plotted in a straight line until the new measurement is available. Fig. 3(c) shows the threshold voltage value for four IGBTs after they were degraded to different number of cycles.

It can be observed that the trends are increasing; Table III shows the average percentage variation due to the degradation process. $V_{\mathrm{GE}, \mathrm{TH}}$ for FUJI IGBT shows an interesting feature. As Fig. 3(b) shows, the initial voltage value of an IGBT in pristine conditions is at a higher level than that observed after 200 degradation cycles. This behavior is commonly observed in semiconductors [19]. For pristine components, there is a stabilization period for the impurities. Then, their change is directly related to the degradation process.

\section{B. Discrete Measurement: $V_{\mathrm{CE}, \mathrm{SAT}}$}

$V_{\mathrm{CE}, \mathrm{SAT}}$ voltage evolution for the life cycle of IGBTs is shown in Fig. 4. The plotting procedure is the same used for $V_{\mathrm{GE}, \mathrm{TH}}$.

The IR IGBT $V_{\mathrm{CE}, \mathrm{SAT}}$ shows a clear decreasing trend, while the FUJI and IXYS IGBTs show an increasing one. Table III summarizes the average percentage variation.

\section{Continuous Measurements During Degradation Cycles}

The data collected during the continuous degradation process is shown in Fig. 5. It can be observed that under the same operating conditions but with a higher number of cycles, the values of $V_{\mathrm{CE}}$ change. A curve-fitting analysis of the IR and FUJI $V_{\mathrm{CE}}$ variation has shown an exponential change with the degradation, where the initial slope is very small and rapidly changes when a critical failure is about to happen.

The trends shown by $V_{\mathrm{CE}, \mathrm{SAT}}$ monitoring are consistent with the behavior observed for the discrete measurements. For the same operating conditions, an increase in $V_{\mathrm{CE}}$ can be seen for 


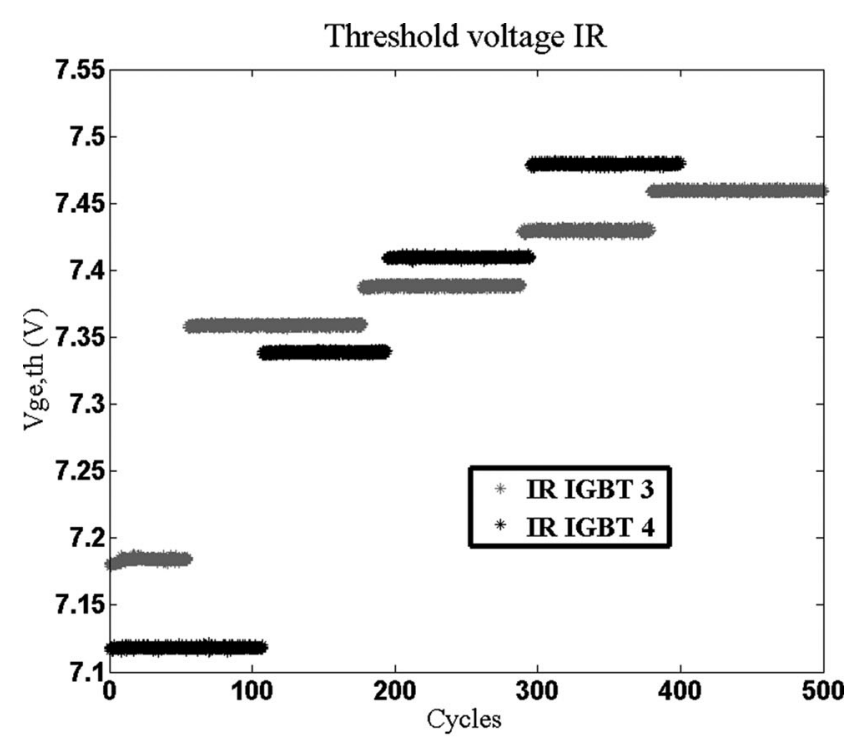

(a)

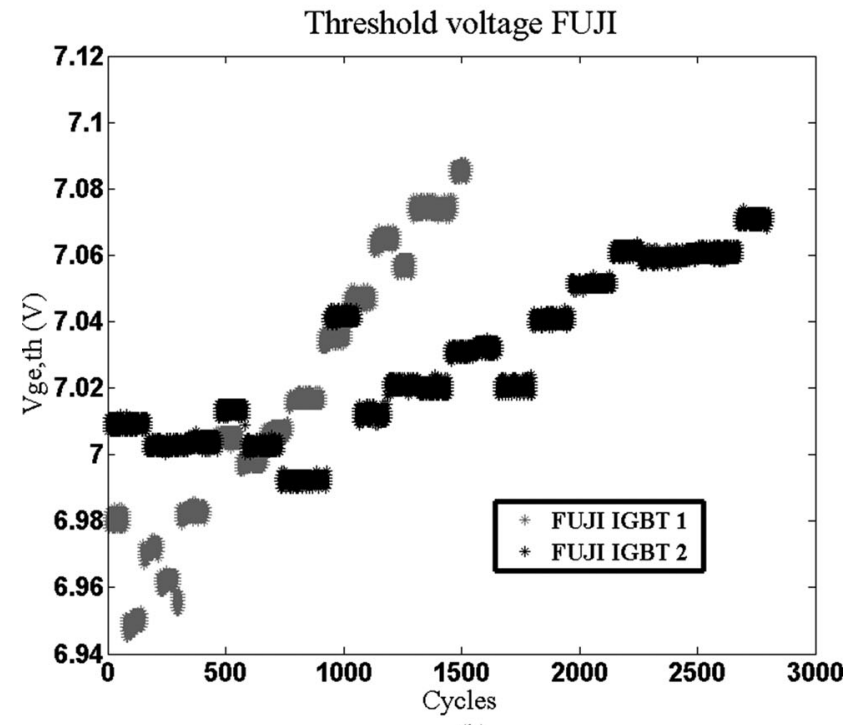

(b)

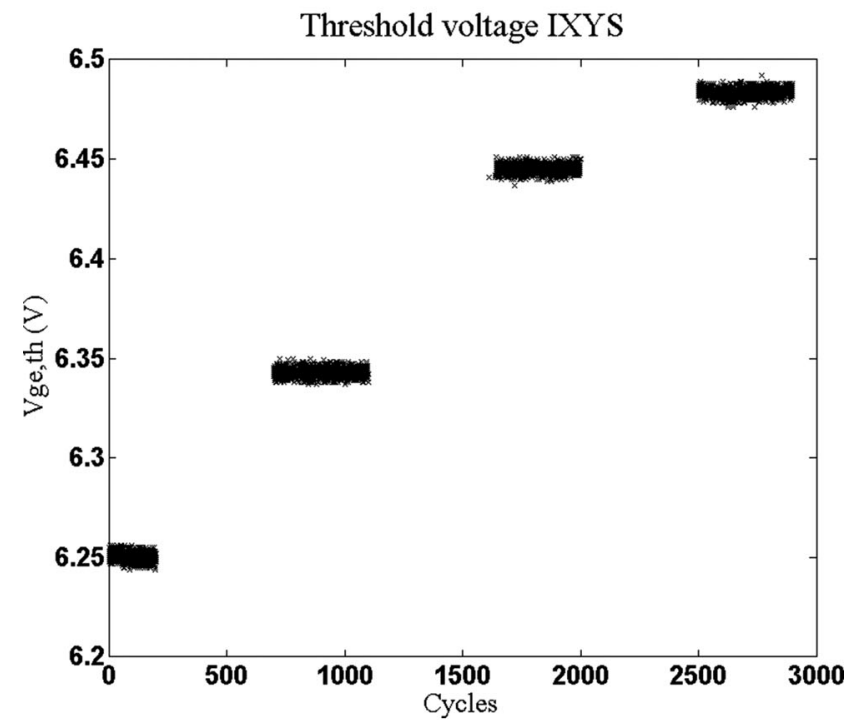

(c)

Fig. 3. IGBT threshold voltage for (a) IR, (b) FUJI, and (c) IXYS.
TABLE III

RESUlTS SUMMARY FOR THREE DIFFERENT IGBT TyPES

\begin{tabular}{|c|c|c|c|}
\hline IGBT Type & IR & FUJI & IXYS \\
\hline $\begin{array}{l}V_{\mathrm{GE}, \mathrm{TH}} \text { trend with } \\
\text { degradation }\end{array}$ & Increase $5 \%$ & Increase $4 \%$ & Increase $4 \%$ \\
\hline $\begin{array}{l}V_{\mathrm{CE}, \mathrm{SAT}} \text { trend with } \\
\text { degradation }\end{array}$ & Decrease $7 \%$ & Increase $4 \%$ & Increase $4 \%$ \\
\hline $\begin{array}{l}\text { Main degradation } \\
\text { mechanism }\end{array}$ & $\begin{array}{c}\text { Die attach } \\
\text { degradation }\end{array}$ & $\begin{array}{l}\text { Voids and cracks on } \\
\text { die attach }\end{array}$ & $\begin{array}{c}\text { Voids and cracks on } \\
\text { die attach }\end{array}$ \\
\hline \multirow[t]{2}{*}{$\begin{array}{l}\text { Degradation } \\
\text { consequences }\end{array}$} & $\begin{array}{c}\text { Increased carrier } \\
\text { concentration }\end{array}$ & $\begin{array}{l}\text { Increased conduction } \\
\text { resistance }\end{array}$ & $\begin{array}{l}\text { Increased conduction } \\
\text { resistance }\end{array}$ \\
\hline & $\begin{array}{l}\text { Decreased } \\
V_{\mathrm{CE}, \mathrm{SAT}}\end{array}$ & Increased $V_{\mathrm{CE}, \mathrm{SAT}}$ & Increased $V_{\mathrm{CE}, \mathrm{SAT}}$ \\
\hline \multirow{2}{*}{$\begin{array}{l}\text { Microscopic } \\
\text { Inspection }\end{array}$} & Damaged gate oxide & Cracks on chip & Cracks on chip \\
\hline & Cracks on chips & No bond-wire lift-off & No bond-wire lift-off \\
\hline
\end{tabular}

both FUJI and IXYS IGBTs, while there is a decrease for IR IGBTs.

A major issue for prognostics assessment is observed. The initial $V_{\mathrm{CE}, \mathrm{SAT}}$ and $V_{\mathrm{GE}, \mathrm{TH}}$ values are not the same among IGBTs of the same type. This means that within the range of variation due to the degradation, the initial $V_{\mathrm{GE}, \mathrm{TH}}$ for a certain IGBT could be the final of another one. As a result, for the implementation of an algorithm a normalization stage will be of major importance.

\section{Continuous Measurements Under Normal Operating Conditions}

Finally, the results obtained for the IXYS IGBTs under normal operating conditions are presented. A new IGBT and a close to end-of-life degraded one (2700 cycles) were tested. Fig. 6(a) shows $V_{\mathrm{CE}}$ signal during operation for both IGBTs. Fig. 6(b) shows $V_{\mathrm{CE}}$ signal for the new and the degraded one for the same TC operating conditions. The gray dots represent the degraded IGBT and the black ones represent the new one. It was observed during the degradation process (see Section VI-C) that $V_{\mathrm{CE}}$ value tends to slightly increase with degradation. Fig. 6(b) shows this behavior, where the gray dots are on top of the black ones. The average maximum value of the degraded IGBT is $1.105 \mathrm{~V}$, while the new one shows an average of $1.060 \mathrm{~V}$. Therefore, we observe a drift of $40 \mathrm{mV}$ on the VCE signal. It must be highlighted that using the IR25750 $V_{\mathrm{CE}}$ sensor along with the current and temperature ones and together with the data acquisition system, we were able to distinguish the variation between the older and the newer IGBT. This shows that if $V_{\mathrm{CE}}$ is measured accurately enough, the degradation can be assessed under normal operating conditions.

\section{E. Degradation Mechanisms Analysis}

Once the degradation process was over, a destructive analysis of the components was carried out in order to discover the degradation mechanisms. Some of the components were cut; others were attacked with $\mathrm{H}_{2} \mathrm{SO}_{4}$ to discover the metallization state on the chip surface. Then, the samples were studied with an optic microscope. 
Vce,sat IR

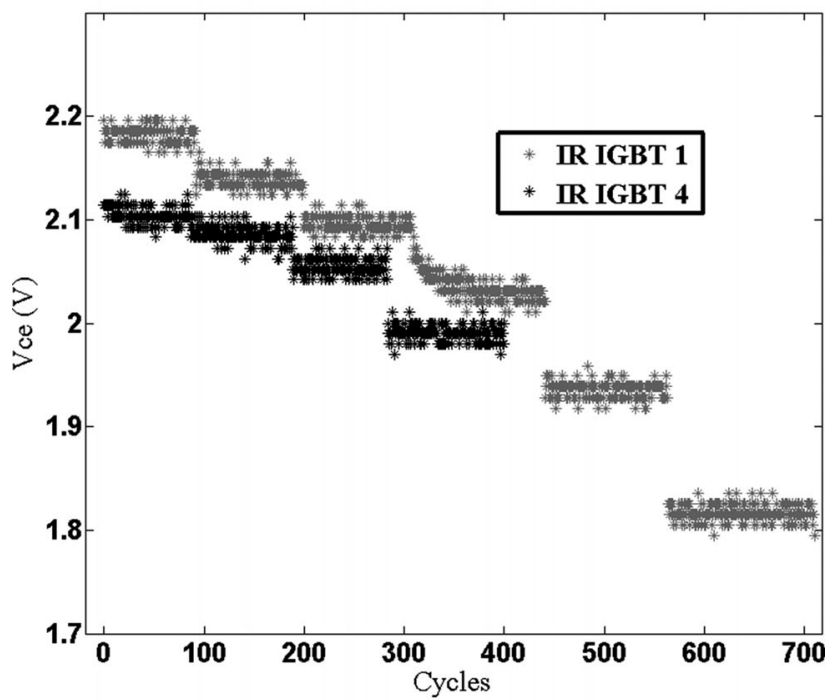

(a)

Vce,sat FUJI

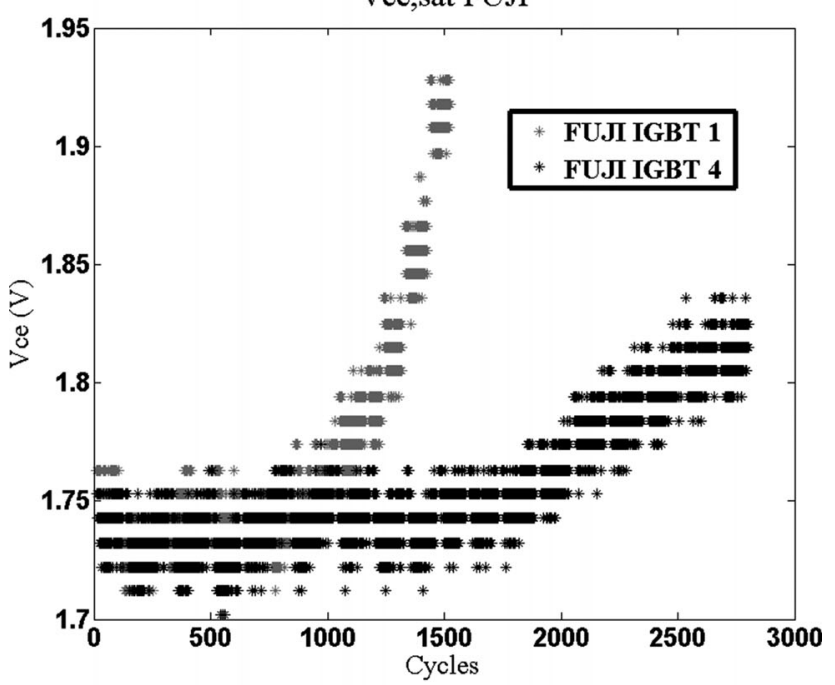

(b)

Vce,sat IXYS

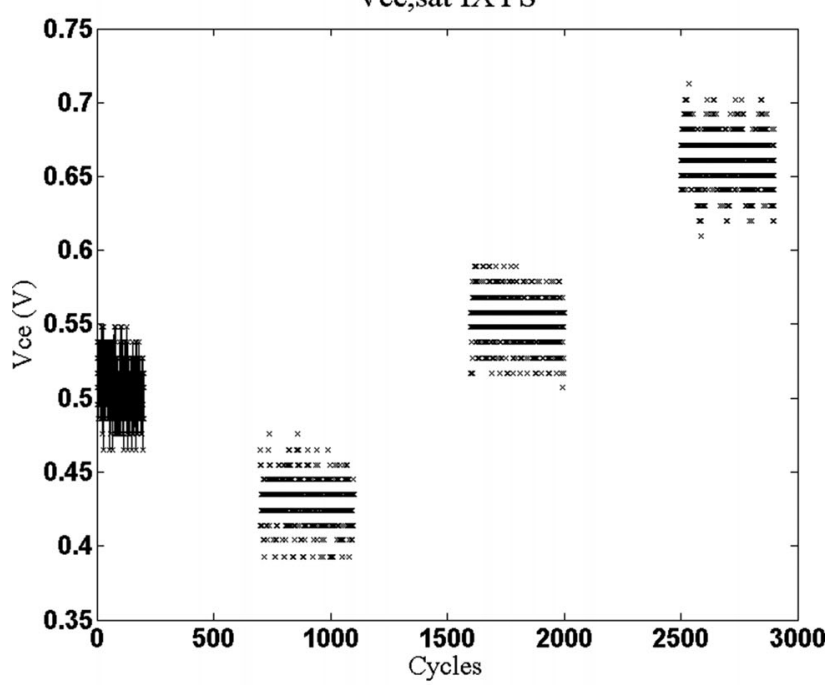

(c)

Fig. 4. IGBTs $V_{\mathrm{CE}, \mathrm{SAT}}$ voltage for (a) IR, (b) FUJI, and (c) IXYS
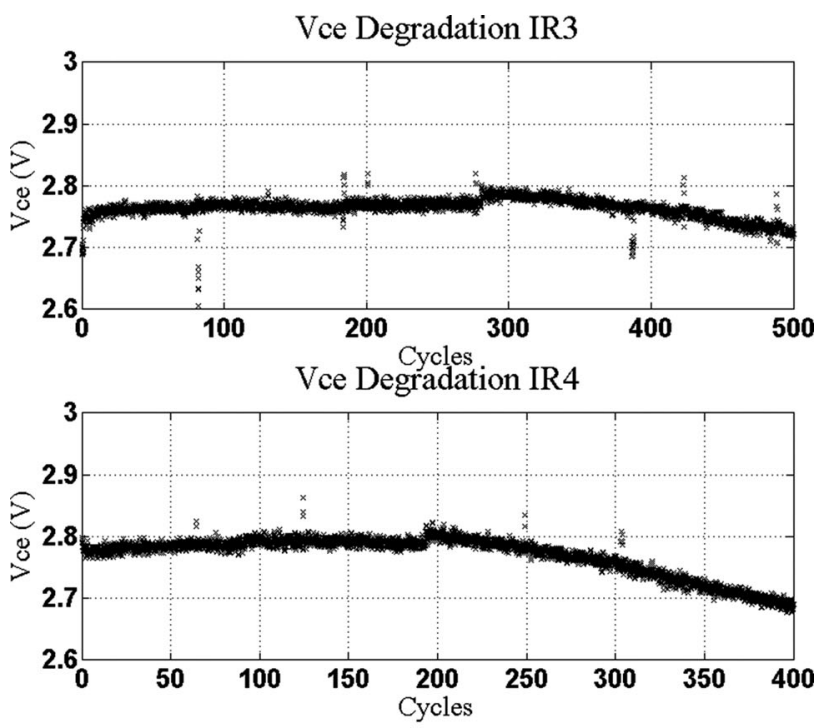

(a)

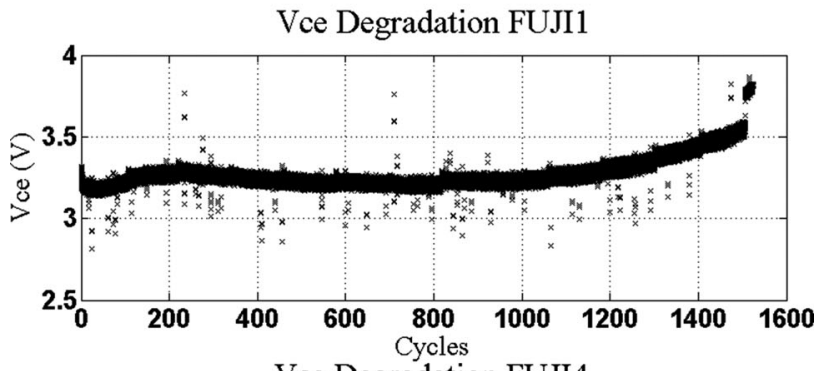

Vce Degradation FUJI4

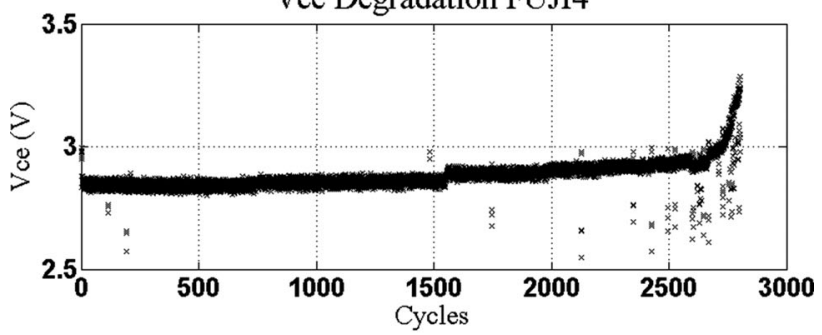

(b)

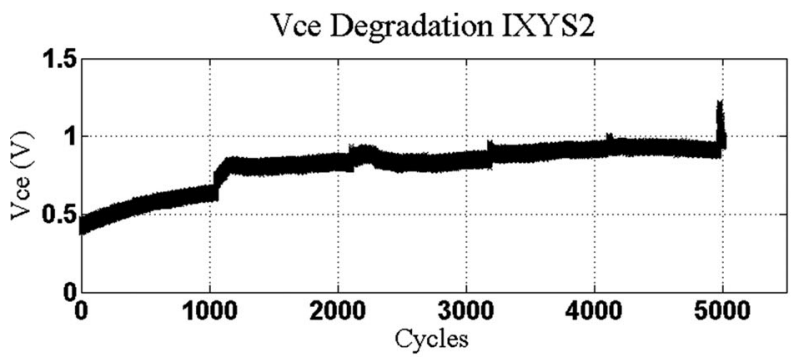

Vce Degradation IXYS3

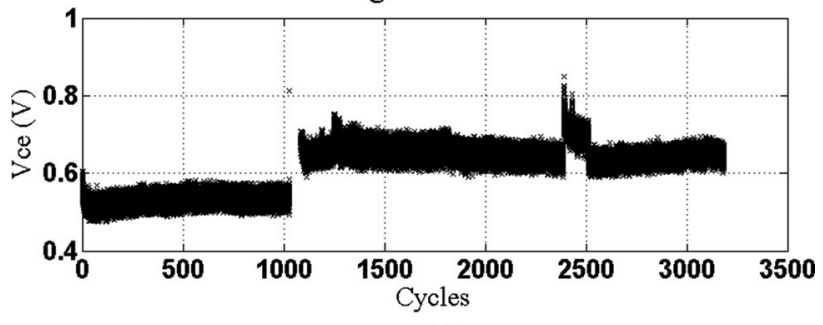

(c)

Fig. 5. IGBTs $V_{\mathrm{CE}, \mathrm{SAT}}$ voltage for continuous degradation for (a) IR, (b) FUJI, and (c) IXYS. 


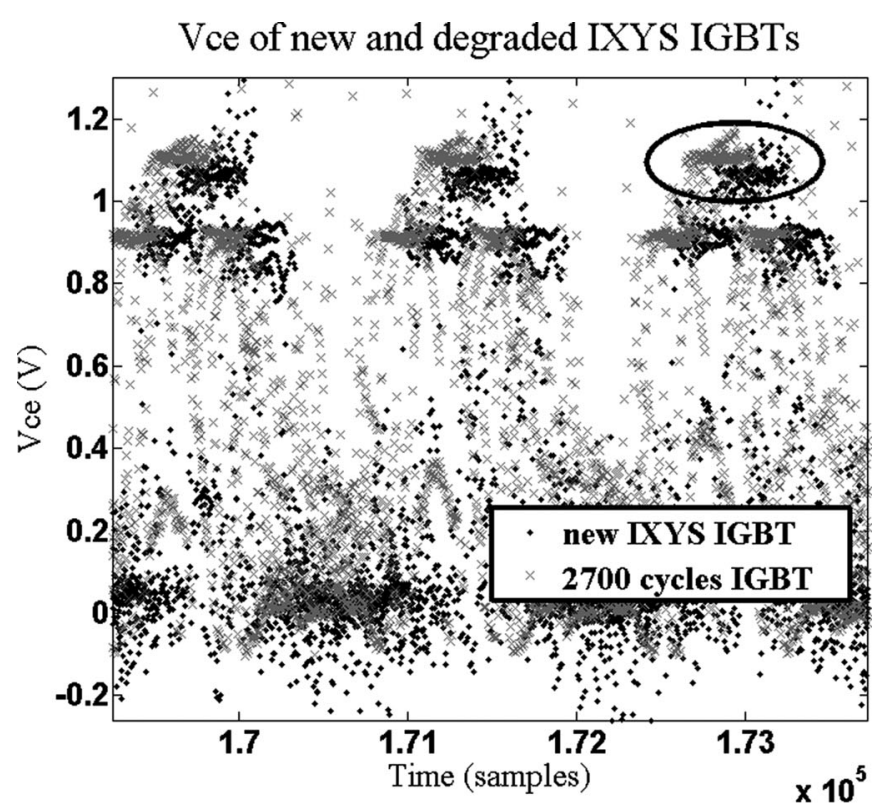

(a)

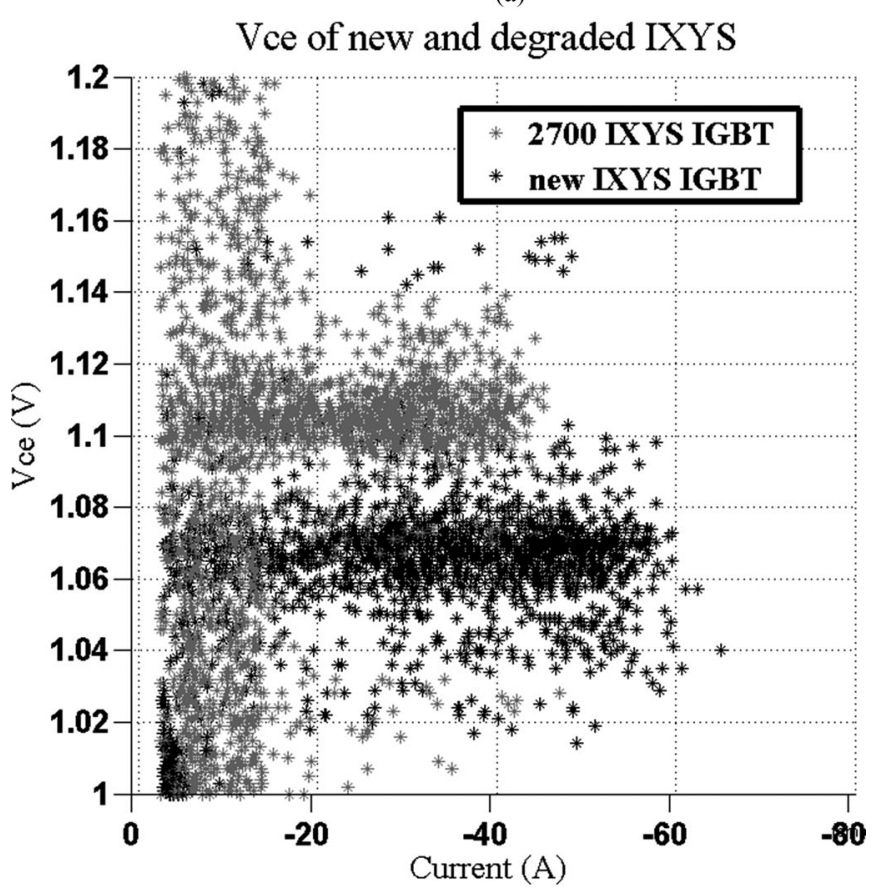

(b)

Fig. 6. (a) $V_{\mathrm{CE}}$ voltage for normal conditions. (b) $V_{\mathrm{CE}}$ value for the same $I_{\mathrm{C}}$ and $T_{\mathrm{c}}$ conditions.

First, the severity of the developed degradation process must be highlighted. Huge damages were observed in the samples as a consequence of the degradation cycles.

A first major difference appears when looking at chip thickness. IR wafer thickness is $380 \mu \mathrm{m}$, while FUJI is $120 \mu \mathrm{m}$ and IXYS is $270 \mu \mathrm{m}$. Following other studies results [11], [15] and observing Fig. 7(b) and (c), it can be concluded that IR degradation mechanism was related to die-attach solder degradation. Crack appearance on chip-solder interface points to die-attach degradation as a main degradation mechanism. Cracks were created at the extremes of the die attach and propagated to the center

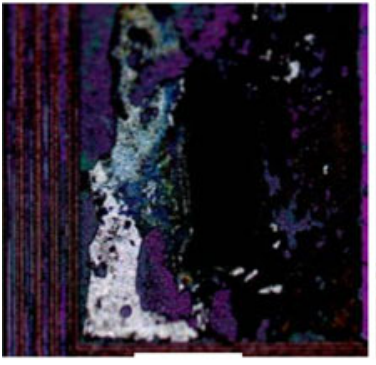

(a)

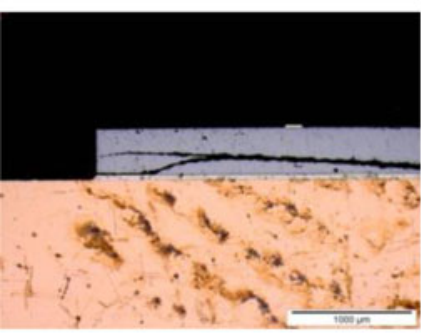

(c)

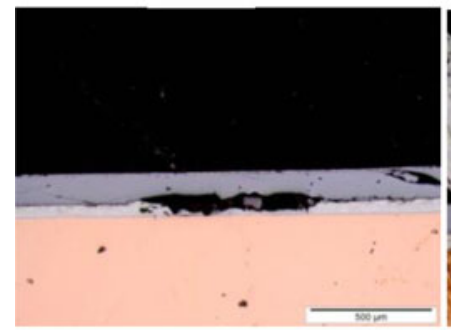

(e)

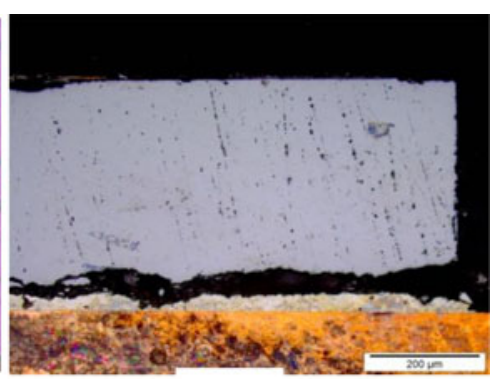

(b)

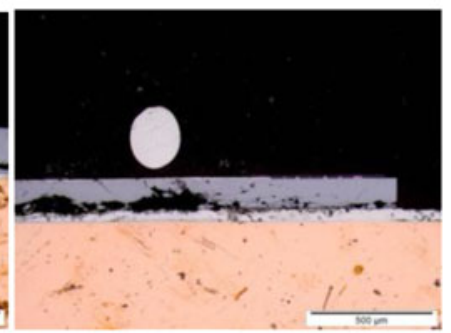

(d)

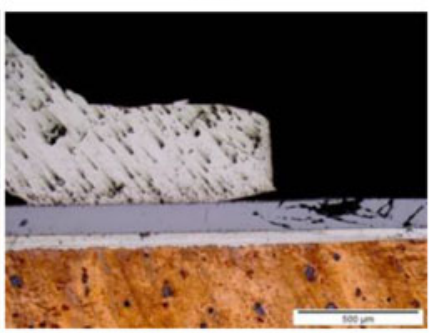

(f)
Fig. 7. (a) Gate-oxide destruction IR; (b) and (c) die-attach degradation on IR1 and IR4; (d) and (e) voids and crack propagation on FUJI1 and 4; and (f) bond wire on FUJI5.

of the die. Die-attach degradation was followed by an increase of temperature at the $\mathrm{PN}$ junction, increasing the intrinsic carrier concentration as well, concluding with a $V_{\mathrm{CE}, \mathrm{SAT}}$ decrease. It can also be observed in Fig. 7(a) that IR IGBTs suffered gate oxide degradation, which explains the increase of $V_{\mathrm{GE}, \mathrm{TH}}$. An increase in $V_{\mathrm{GE}, \mathrm{TH}}$ is related to gate oxide damage due to hot carrier injection resulting in charge trap [10].

Other studies concluded that the increase of $V_{\mathrm{CE}, \mathrm{SAT}}$ in IGBT modules is a consequence of bond-wire liftoff [11], [14], [15]. However, after attacking one of the FUJI samples with $\mathrm{H}_{2} \mathrm{SO}_{4}$ and looking at Fig. 7(f), the operation of bond-wire liftoff failure mechanism was discarded. The attachment of the bond wires showed full contact. Observing Fig. 7(d) related to FUJI IGBTs, a great destruction of the chip was discovered. It included void and crack propagation on the die attach as well. Similar cracks were observed on IXYS IGBTs. It was concluded that the destruction on the die attach increased the conduction resistance, and therefore, $V_{\mathrm{CE}, \mathrm{SAT}}$ increased for a given current value. This effect demonstrated to have more importance on FUJI and IXYS IGBTs than the effect of intrinsic carrier concentration, as explained for IR IGBTs case. It can be concluded that the thermomechanical fatigue stress induced on the die attach was the main degradation mechanism. 


\section{F. Results Summary}

A summary extracted from the results is shown in Table III. The percentage variation of the variables due to the degradation process is shown. The main degradation mechanisms and their consequences are presented as well. Finally, the physical damages observed through microscopic inspection are included.

\section{DISCUSSION AND CONCLUSION}

First, the tests demonstrated IGBT life cycles greatly vary depending on the manufacturing technology. The tests confirmed the stochasticity of the degradation process of IGBTs, even under the same degrading conditions. The variability observed on the standard deviation of the degradation cycles confirms condition-based maintenance as a convenient approach.

Different prognostic variables were analyzed taking into account not only the information provided but practical issues such as intrusiveness and measuring frequency as well. The studies have been developed both with laboratory equipment and a measuring system ready for in-vehicle online monitoring. The results were compared and validated with previous studies [15].

It was concluded that the triplet formed by $T_{C}, I_{C}$, and $V_{\mathrm{CE}}$ variables provides a good framework for prognostics. Mainly, we claim that $V_{\mathrm{CE}}$ changes its value with degradation for a given current and temperature value, and therefore, the variables must be accurately measured. The variation in the signal can be considered to be very small, on the order of hundredths of a millivolt, following other reports [14]. With the correct signal sampling and the sensors employed in this study, the assessment of the degradation is a real fact. Under normal operating conditions, a difference between degraded and nondegraded IGBTs was observed.

In order to overcome signals noise and uncertainty problems due to the highly dynamic conditions and the minute variation of $V_{\mathrm{CE}}$, several methodologies could be undertaken. First, statistical inference techniques and machine learning algorithms have been proposed [20]. This approach leads to an intensive data pre-processing stage in order to obtain degradation patterns. To avoid the influence on prognostics of data outliers, the statement of thresholds and a minimum number of measurements outside the boundaries are suggested. This approach and the data obtained from continuous measurements under normal operative conditions were employed to train a self-organizing map (SOM) algorithm for IGBT monitoring [21]. Hence, it is demonstrated that it is possible to detect the minute variation of $V_{\mathrm{CE}}$ online with commercial sensors.

A study of the degradation mechanisms was also addressed. Thermomechanical stress-induced cracks were the main degradation mechanism. However, the selected degradation temperatures produced severe damages, probably addressing other, yet slower, degradation mechanisms at the same time. Therefore, more consistent and regular patterns of the variables would be expected if the components were operated for a longer period of time within the safe operating area (SOA).

To sum up, accelerated aging tests were run for three different IGBT types. The results of the different measurements were analyzed and useful results for a PHM system were presented.
Prognostic systems based on three variables $\left(T_{C}, I_{C}, V_{\mathrm{CE}}\right)$ are proposed.

\section{ACKNOWLEDGMENT}

The authors would like to thank S. Gonzalez and A. Gomez from the Department of Materials at CEIT for their help and contribution to this work.

\section{REFERENCES}

[1] M. Pecht, Prognostics and Health Management of Electronics. New York, NY, USA: Wiley, 2008.

[2] J. W. Sheppard, M. A. Kaufman, and T. J. Wilmer, "IEEE standards for prognostics and health management," IEEE Aerospace Electron. Syst. Mag., vol. 24, no. 9, pp. 34-41, Sep. 2009.

[3] Y. Song and B. Wang, "Survey on reliability of power electronic systems," IEEE Trans. Power Electron., vol. 28, no. 1, pp. 591-604, Jan. 2013.

[4] A. Hensler, J. Lutz, M. Thoben, and K. Guth, "First power cycling results of improved packaging technologies for hybrid electrical vehicle applications," in Proc. IEEE 6th Int. Conf. Integr. Power Electron. Syst., pp. 1-5, Mar. 16-18. 2010.

[5] B. Ji, V. Pickert, W. Cao, and B. Zahawi, "In situ diagnostics and prognostics of wire bonding faults in IGBT modules for electric vehicle drives," IEEE Trans. Power Electron., vol. 28, no. 12, pp. 5568-5577, Dec. 2013.

[6] B. Caulfield, S. Farrell, and B. McMahon, "Examining individuals preferences for hybrid electric and alternatively fuelled vehicles," Transport Policy, vol. 17, no. 6, pp. 381-387, 2010.

[7] P. Baraldi, F. Di Maio, M. Rigamonti, E. Zio, A. Galarza, D. Astigarraga, I. Unanue, A. Ruddle, and S. Rantala, "A procedure for practical prognostics and health monitoring of fully electric vehicles for enhanced safety and reliability," in Proc. 5th IET Hybrid Electr. Veh. Conf., 2014, p. 1.

[8] M. Rigamonti, P. Baraldi, E. Zio, D. Astigarraga, and A. Galarza, "Particle filter-based prognostics for an electrolytic capacitor working in variable operating conditions," IEEE Trans. Power Electron., vol. 31, no. 2 pp. $1567-1575$, Feb. 2016.

[9] H. Huang and P. A. Mawby, "A lifetime estimation technique for voltage source inverters," IEEE Trans. Power Electron., vol. 28, no. 8, pp. 4113-4119, Aug. 2013.

[10] S. Yang, D. Xiang, A. Bryant, P. Mawby, L. Ran, and P. Tavner, "Condition monitoring for device reliability in power electronic converters: A review," IEEE Trans. Power Electron., vol. 25, no. 11, pp. 2734-2752, Nov. 2010

[11] H. Oh, B. Han, P. McCluskey, C. Han, and B. D. Youn, "Physics-offailure, condition monitoring, and prognostics of insulated gate bipolar transistor modules: A review," IEEE Trans. Power Electron., vol. 30, no. 5, pp. 2413-2426, May 2015.

[12] J. Celaya, P. Wysocki, V. Vashchenko, S. Saha, and K. Goebel, "Accelerated aging system for prognostics of power semiconductor devices," in Proc. IEEE AUTOTESTCON, 2010, p. 1.

[13] R. Amro, J. Lutz, J. Rudzki, R. Sittig, and M. Thoben, "Power cycling at high temperature swings of modules with low temperature joining technique," in Proc. IEEE Int. Symp. Power Semicond. Devices IC's, 2006, p. 1.

[14] V. Smet, F. Forest, J. Huselstein, F. Richardeau, Z. Khatir, S. Lefebvre, and M. Berkani, "Ageing and failure modes of IGBT modules in hightemperature power cycling," IEEE Trans. Ind. Electron., vol. 58, no. 10, pp. 4931-4941, Oct. 2011

[15] N. Patil, J. Celaya, D. Das, K. Goebel, and M. Pecht, "Precursor parameter identification for insulated gate bipolar transistor (IGBT) prognostics," IEEE Trans. Rel., vol. 58, no. 2, pp. 271-276, Jun. 2009.

[16] B. Sedano, A. R. Ruddle, I. Unanue, L. Low, D. Astigarraga, I. Ibarra, I. Cerro, and A. Galarza, "HEMIS: Electrical powertrain health monitoring for increased safety of FEVs," Chem. Eng. Trans., vol. 33, pp. 781-786, 2013.

[17] R. Bayerer, T. Herrmann, T. Licht, J. Lutz, and M. Feller, "Model for power cycling lifetime of IGBT modules-Various factors influencing lifetime," in Proc. 2008 5th Int. Conf. Integr. Power Syst., VDE, 2008, pp. 1-6.

[18] Datasheet NI-USB-6259. (2014). [Online]. Available: http://www.ni.com/ datasheet/pdf/en/ds-20

[19] A. Christou and W. M. Webb, "Reliability of compound analogue semiconductor integrated circuits," Reliability Information Analysis Center (RIAC), 2006. 
[20] P. Tamilselvan, P. Wang, and M. Pecht, "A multi-attribute classification fusion system for insulated gate bipolar transistor diagnostics," Microelectron. Rel., vol. 53, no. 8, pp. 1117-1129, 2013.

[21] M. Rigamonti, P. Baraldi, E. Zio, A. Alessi, D. Astigarraga, and A. Galarza, "A self-organizing map-based monitoring system for insulated gate bipolar transistors operating in fully electric vehicle," in Proc. Annual Conf. Prognostic Health Manage. Society 2015, vol. 6, pp. 253-261, 2015.

[22] K. Rajashekara, "Present status and future trends in electric vehicle propulsion technologies," IEEE J. Emerging Select. Topics Power Electron. vol. 1, no. 1, pp. 3-10, Mar. 2013

[23] H. Wang, M. Liserre, F. Blaabjerg, P. de Place Rimmen, J. B. Jacobsen, T. Kvisgaard, and J. Landkildehus, "Transitioning to physics-of-failure as a reliability driver in power electronics," IEEE J. Emerging Select. Topics Power Electron., vol. 2, no. 1, pp. 97-114, Mar. 2014. 